\title{
Polymorphisms in early neurodevelopmental genes affect natural variation in alcohol sensitivity in adult drosophila
}

\author{
Tatiana V. Morozova ${ }^{1 \dagger}$, Wen Huang ${ }^{1 \dagger}$, Victoria A. Pray ${ }^{1}$, Thomas Whitham ${ }^{1,2}$, Robert R. H. Anholt \\ and Trudy F. C. Mackay ${ }^{1 *}$
}

\begin{abstract}
Background: Alcohol abuse and alcoholism are significant public health problems, but the genetic basis for individual variation in alcohol sensitivity remains poorly understood. Drosophila melanogaster presents a powerful model system for dissecting the genetic underpinnings that determine individual variation in alcohol-related phenotypes. We performed genome wide association analyses for alcohol sensitivity using the sequenced, inbred lines of the D. melanogaster Genetic Reference Panel (DGRP) together with extreme QTL mapping in an advanced intercross population derived from sensitive and resistant DGRP lines.

Results: The DGRP harbors substantial genetic variation for alcohol sensitivity and tolerance. We identified 247 candidate genes affecting alcohol sensitivity in the DGRP or the DGRP-derived advanced intercross population, some of which met a Bonferroni-corrected significance threshold, while others occurred among the top candidate genes associated with variation in alcohol sensitivity in multiple analyses. Among these were candidate genes associated with development and function of the nervous system, including several genes in the Dopamine decarboxylase (Ddc) cluster involved in catecholamine synthesis. We found that 58 of these genes formed a genetic interaction network. We verified candidate genes using mutational analysis, targeted gene disruption through RNAi knock-down and transcriptional profiling. Two-thirds of the candidate genes have been implicated in previous Drosophila, mouse and human studies of alcohol-related phenotypes.
\end{abstract}

Conclusions: Individual variation in alcohol sensitivity in Drosophila is highly polygenic and in part determined by variation in evolutionarily conserved signaling pathways that are associated with catecholamine neurotransmitter biosynthesis and early development of the nervous system.

Keywords: Drosophila Genetic Reference Panel, Genome-wide association analysis, Extreme QTL mapping, Alcohol tolerance, Genetic networks

\section{Background}

As a common by-product of natural fermentation, alcohol has been an integral part of human culture since early recorded history. The inebriating effects of alcohol have been recorded since biblical times. In today's society, excessive alcohol consumption is the most

\footnotetext{
* Correspondence: trudy_mackay@ncsu.edu

${ }^{\dagger}$ Equal contributors

'Department of Biological Sciences, W. M. Keck Center for Behavioral Biology and Program in Genetics, North Carolina State University, Box 7614, Raleigh, NC 27695, USA

Full list of author information is available at the end of the article
}

widespread substance abuse problem with substantial socioeconomic impact.

Different human populations vary in alcohol consumption and in susceptibility to the physiological effects of alcohol, as do individuals within populations [1-4]. The extent to which individuals develop tolerance to the physiological effects of alcohol is a contributing factor to the development of addiction. Studies on genetic susceptibility to the physiological effects of alcohol in human populations have mostly focused on aspects of addiction. Linkage and association studies for candidate genes [5-10] as well as genome-wide analyses [10-15] have

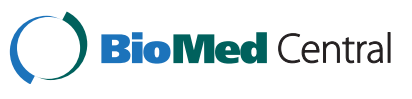

(C) 2015 Morozova et al. Open Access This article is distributed under the terms of the Creative Commons Attribution 4.0 International License (http://creativecommons.org/licenses/by/4.0/), which permits unrestricted use, distribution, and reproduction in any medium, provided you give appropriate credit to the original author(s) and the source, provide a link to the Creative Commons license, and indicate if changes were made. The Creative Commons Public Domain Dedication waiver (http://creativecommons.org/publicdomain/zero/1.0/) applies to the data made available in this article, unless otherwise stated. 
implicated neurotransmitter systems associated with the mesolimbic reward pathway and enzymes that contribute to alcohol metabolism. However, results from genome-wide association (GWA) studies in people, as well as information from studies on animal models, indicate that additional regulatory processes are involved in alcohol addiction and that the genetic architecture that predisposes individuals to addiction is complex $[5,16-20]$.

Although addiction is undeniably an important alcohol-related phenotype, acute intoxication is a major contributor to the socioeconomic costs of alcohol abuse. Few studies have focused on acute alcohol sensitivity within the range of normal alcohol intake across a population. Disentangling the genetic and environmental contributions that shape alcohol-related phenotypes in human populations is challenging because alcohol exposure and other contributing environmental factors cannot be controlled. Further complications arise because different studies have utilized different measurements to document alcohol-related phenotypes. Partitioning the relative contributions of genotype, ethanol exposure and the interaction between genotype and environment is more readily accomplished in animal models in which both the genetic background and environment can be controlled and alcoholrelated phenotypes quantified accurately. Based on the principle of evolutionary conservation, animal models can provide general insights in fundamental biological processes affected by alcohol exposure [16, 18, 21-24].

Drosophila melanogaster provides such a model. Assays have been developed to precisely quantify sensitivity to alcohol by measuring alcohol-induced knock-down time [25, 26], and flies exposed to ethanol undergo physiological and behavioral changes that resemble human alcohol intoxication [27, 28]. Previous studies on alcohol sensitivity in Drosophila have identified cyclic AMP signaling [29, 30], alcohol metabolism (ADH) [31-33] and malic enzyme activity [34, 35] as focal pathways that mediate responses to alcohol exposure. Malic enzyme serves as a metabolic switch to redirect energy metabolism toward fatty acid biosynthesis. Results from the Drosophila model guided the identification of association between polymorphisms in cytosolic malic enzyme with human alcohol consumption in the Framingham Heart Study Offspring cohort [34]. The genetic architecture that underlies alcohol sensitivity and induction of tolerance, however, is more complex; it involves transcriptional regulators that alter gene expression [35-37] and consists of intricate genetic networks $[34,38]$. In a previous study we have shown that acute exposure to ethanol results in altered transcript abundance levels of chemoreceptor and detoxification genes, whereas the subsequent development of tolerance is accompanied by changes in transcript abundances of metabolic enzymes [35]. However, most studies on the genetic basis of alcohol sensitivity have focused on effects of single genes. A major challenge in understanding the biological effects of alcohol is to identify the interacting networks of segregating loci that contribute to natural variation in alcohol sensitivity.

Here, we performed two complementary genome-wide association analyses to explore the genetic basis of natural variation in alcohol sensitivity in Drosophila. We performed genome wide association (GWA) analyses for alcohol-related phenotypes using the sequenced inbred lines of the Drosophila melanogaster Genetic Reference Panel (DGRP) [39, 40], and extreme QTL mapping analyses $[41,42]$ utilizing an advanced intercross population (AIP) derived from sensitive and resistant DGRP lines. We identified 247 high confidence candidate genes and placed them in genetic and physical interaction networks. These candidate genes are associated with development and function of the nervous system and include several genes involved in catecholamine synthesis. We confirmed the role of several candidate genes in alcohol sensitivity by functional analyses of mutations and gene expression levels. Remarkably, $66.8 \%$ of the candidate genes have been implicated in previous Drosophila, mouse and human studies of alcohol-related phenotypes, suggesting that these candidate genes and genetic networks are associated with evolutionarily conserved processes that underlie natural variation in sensitivity to alcohol.

\section{Results}

\section{Natural variation for alcohol sensitivity}

We took advantage of natural variation in the DGRP to analyze phenotypic variation in responses to acute and repeated exposures to ethanol. We measured alcohol knockdown time (Mean Elution Time, MET) in an "inebriometer" [34, 35] after a single (acute) alcohol exposure (E1), and after a second exposure (E2) following a $2 \mathrm{~h}$ recovery period, separately for males and females. We found considerable genetic variation in alcohol sensitivity among the DGRP lines (Fig. 1, Additional file 1: Table S1, Additional file 2).

We expressed individual METs of the 205 DGRP lines as deviations from the control mean of the Canton $S$ (B) line for the appropriate date and sex. Over the course of the experiments, the Canton $S$ (B) elution time after a single ethanol exposure has a mean of $6.1 \pm 0.1$ and $6.05 \pm$ $0.1 \mathrm{~min}$ for males and females, respectively. The METs after the first exposure ranged from 1.2 to $15.5 \mathrm{~min}$ in females and 2.1 to $16.1 \mathrm{~min}$ in males $\left(P_{\text {Line }}<0.0001\right)$, with a broad sense heritability of $H^{2}=0.42$. The averages for DGRP males and females are $7.75 \pm 0.02$ and $7.05 \pm 0.02 \mathrm{~min}$, respectively. The Canton $S$ (B) males 
and females ranked $69 /(205+1)$ and $49 /(205+1)$ among the DGRP lines.

The METs after the second exposure were on average higher, reflecting the development of tolerance, and ranged from 4.0 to $17.4 \mathrm{~min}$ in females and 3.9 to $21 \mathrm{~min}$ in males $\left(P_{\text {Line }}<0.0001\right)$, with $H^{2}=0.38$ (Fig. 1 , Additional file 1: Table S1). Genetic variation for alcohol sensitivity is partially context-dependent. Although the genetic (Additional file 1: Table S1) and phenotypic (Additional file 3: Figure S1) correlations are high between males and females for E1 and E2, and between E1 and E2 for males and females, the significant Line $\times$ Sex and Line $\times$ Exposure interaction terms $(P<0.0001)$ (Additional file 1: Table S1) reflect genetic variation in the magnitude of sexual dimorphism in E1 and E2 as well as genetic variation in the magnitude of induction of tolerance in the two sexes. Genetic variation in the induction of tolerance can be quantified for each line as the scaled difference in mean elution time between the second and first exposures [43].

Induction of tolerance ranged from -0.75 to $4 \mathrm{~min}$ and -1.3 to $4 \mathrm{~min}$ for females and males, respectively.

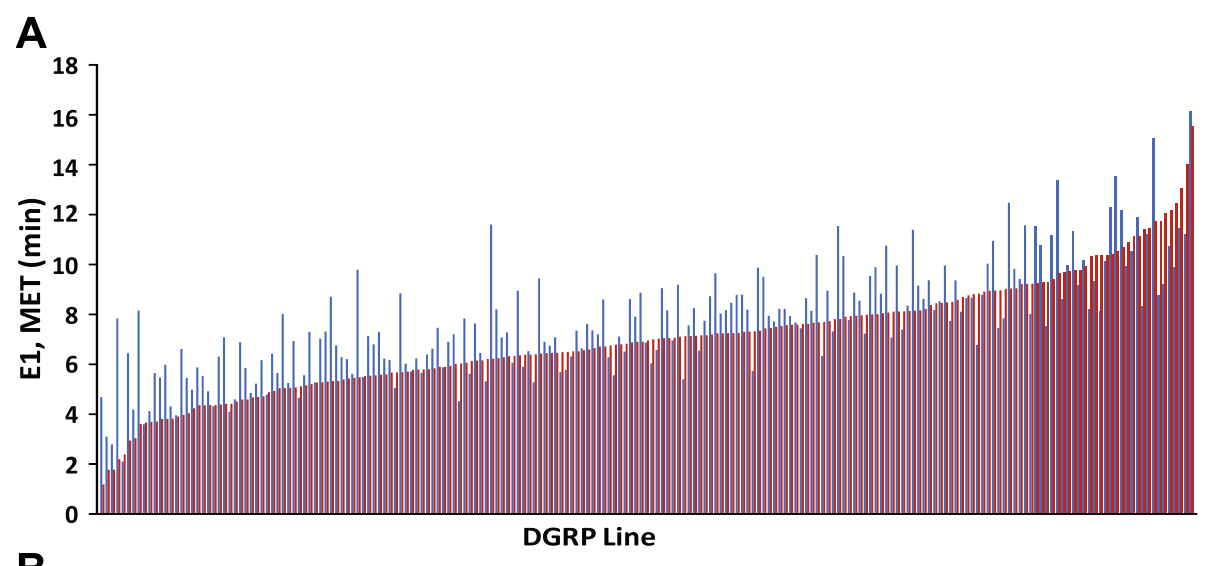

B
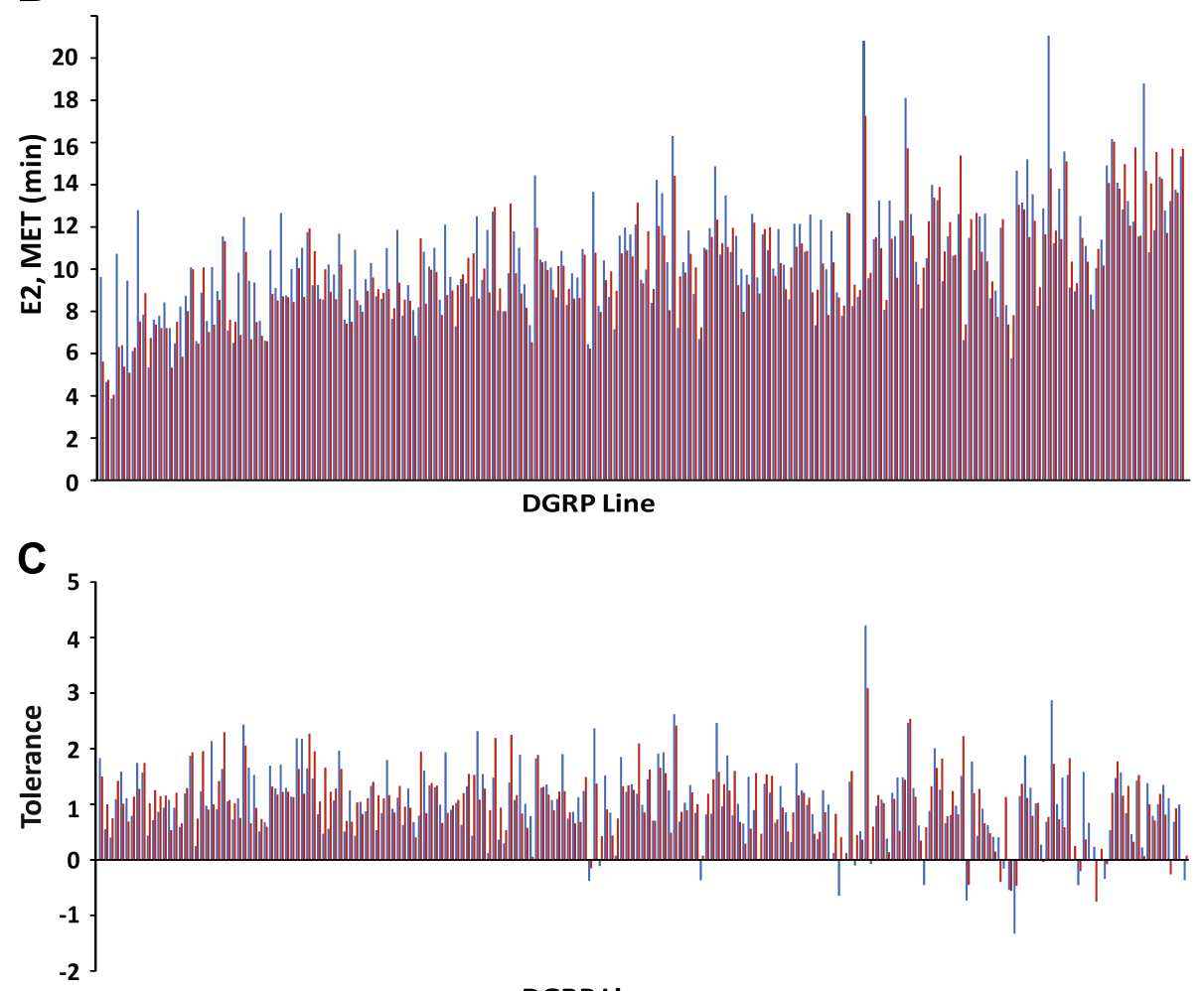

DGRP Line

Fig. 1 Variation in Mean Elution Time (MET) among the 205 inbred lines of the Drosophila melanogaster Genetic Reference Panel (DGRP). a Variation in response to initial alcohol exposure (E1). b Variation in response to a second alcohol exposure (E2). $\mathbf{c}$ Variation in tolerance. Red bars represent females and blue bars males 
Several lines were unable to develop tolerance, and, among the majority that did, the magnitude of tolerance varied continuously (Fig. 1).

\section{GWA analyses for alcohol sensitivity in the DGRP}

We performed genome-wide single variant association tests for sensitivity to acute and repeated ethanol exposures as well as induction of tolerance for the DGRP lines, using 1,891,456 DNA sequence variants with minor allele frequencies greater than 0.05 [39]. We performed these analyses for males and females separately within each treatment, as well as using the differences in alcohol sensitivity between the sexes as phenotypic values to identify alleles that modulate sexual dimorphism in alcohol sensitivity. We considered variants with a $P$-value smaller than $5 \times 10^{-5}$ to be nominally significant (Additional files 4, 5 and 6).

Given the large numbers of tests performed and the relatively small number of DGRP lines, only variants with large effects can achieve significance following a strict Bonferroni correction for multiple tests $\left(P<2.64 \times 10^{-8}\right)$. Three closely linked SNPs in strong linkage disequilibrium (LD) between 3L_2180717 and 3L_2180921, in a gene desert approximately $8 \mathrm{~kb}$ upstream of CG15820 and $5 \mathrm{~kb}$ downstream of CG13810, affect female sensitivity to an acute alcohol exposure; and one SNP at X_7651622 in the second intron of $c t$ affects male sensitivity to a second exposure at the Bonferroni-corrected significance threshold. $c t$, an early developmental homeobox transcription factor with pleiotropic effects on multiple phenotypes, has been implicated in alcohol sensitivity in Drosophila [44], as have its orthologs in mice $[45,46]$ and humans $[14,47]$.

The genetic correlations of METs between ethanol exposures and males and females are high. Therefore, the different analyses partially serve as independent replicates of alcohol sensitivity, and variants and genes in common among the top ranking associations from the different analyses are likely to be true positives, even though they do not achieve formal statistical significance in their individual analyses. Indeed, 75 genes were tagged by top variants in one or more treatment/sex combinations $(P=0.001$ by 1,000 permutations; Additional file 7$)$. Remarkably, 57 (70\%) of these genes were previously associated with alcohol sensitivity in Drosophila, mice and/or humans, and five have been functionally validated previously in Drosophila (Additional file 7).

\section{Extreme QTL Mapping}

The advantage of the Drosophila system is that we can construct a trait-specific, advanced intercross outbred population (AIP) from extreme DGRP lines. The sample size of the AIP is not limiting, giving increased power to detect variants with smaller effects than in the DGRP. Further, the DGRP GWA analyses focused on common variants, because rare alleles are prone to false positives [39], but may give rise to large phenotypic effects [48]. In contrast, any variant private to one of the parental lines used to construct the AIP will be at intermediate frequency if the number of parental lines is small, thus enabling evaluation of the contribution of alleles with MAF $<0.05$ to natural variation in alcohol sensitivity. Finally, the AIP serves as an independent validation of candidate genes identified in the DGRP.

We constructed an AIP for alcohol sensitivity by crossing six DGRP lines with divergent and extreme alcohol sensitivities (three sensitive and three resistant lines for both E1 and E2) to generate a base population in which all lines were equally represented. We maintained this population by random mating at large census size for over 25 generations. Beginning at generation 25, we scored 2,000 males and 2,000 females from the AIP for ethanol sensitivity after acute (E1) or repeated (E2) ethanol exposures, and selected the $10 \%$ most sensitive and resistant males and females for each treatment (Fig. 2). We performed bulk DNA sequencing on DNA pooled from these extreme individuals and performed an extreme QTL mapping GWA analysis [41, 49] by comparing differences in allele frequencies between the pools. Alleles with divergent frequencies between sensitive and resistant DNA pools are either themselves causal alleles or they are in LD with causal alleles affecting the trait.

Consistent with the increased power of extreme QTL mapping in an AIP, we found a total of 60 variants in or near 53 genes associated with alcohol sensitivity in the four extreme QTL GWA analyses (Additional files 7 and 8 ) at a Bonferroni-corrected significance threshold $\left(P<5 \times 10^{-8}\right)$ with a total of 1,461 variants passing a nominal threshold of $P<10^{-5}$. Notably, several of these genes have been implicated previously in Drosophila alcohol-related phenotypes, including bun, Catsup, CG2064, CG2065, CG3326, CG9005, CG9674, for, ham, hig, Lar, Lim3, nudC, Pde11, toc and vir-1 [34-38, 44, 50, 51] (Additional file 7). Several of these are located in the $D d c$ gene cluster on chromosome $2 L$, which harbors closely linked genes involved in catecholamine metabolism.

The $D d c$ gene cluster is of particular interest with regard to alcohol sensitivity in Drosophila. Dopamine has been implicated in aversive conditioning towards repellent odorants [52, 53]. However, dopaminergic neurotransmission appears to be essential for development of conditioned preference for ethanol-associated cues [54]. Both octopamine and dopamine have been implicated in appetitive reward signaling in response to a sugar stimulus $[55,56]$. Octopamine-mediated reinforcement depends on interactions with dopaminergic neurons in the mushroom bodies $[55,56]$. Dopaminergic neurons in the protocerebral anterior medial cluster that project to the medial lobes of the mushroom bodies [55] have been implicated in 

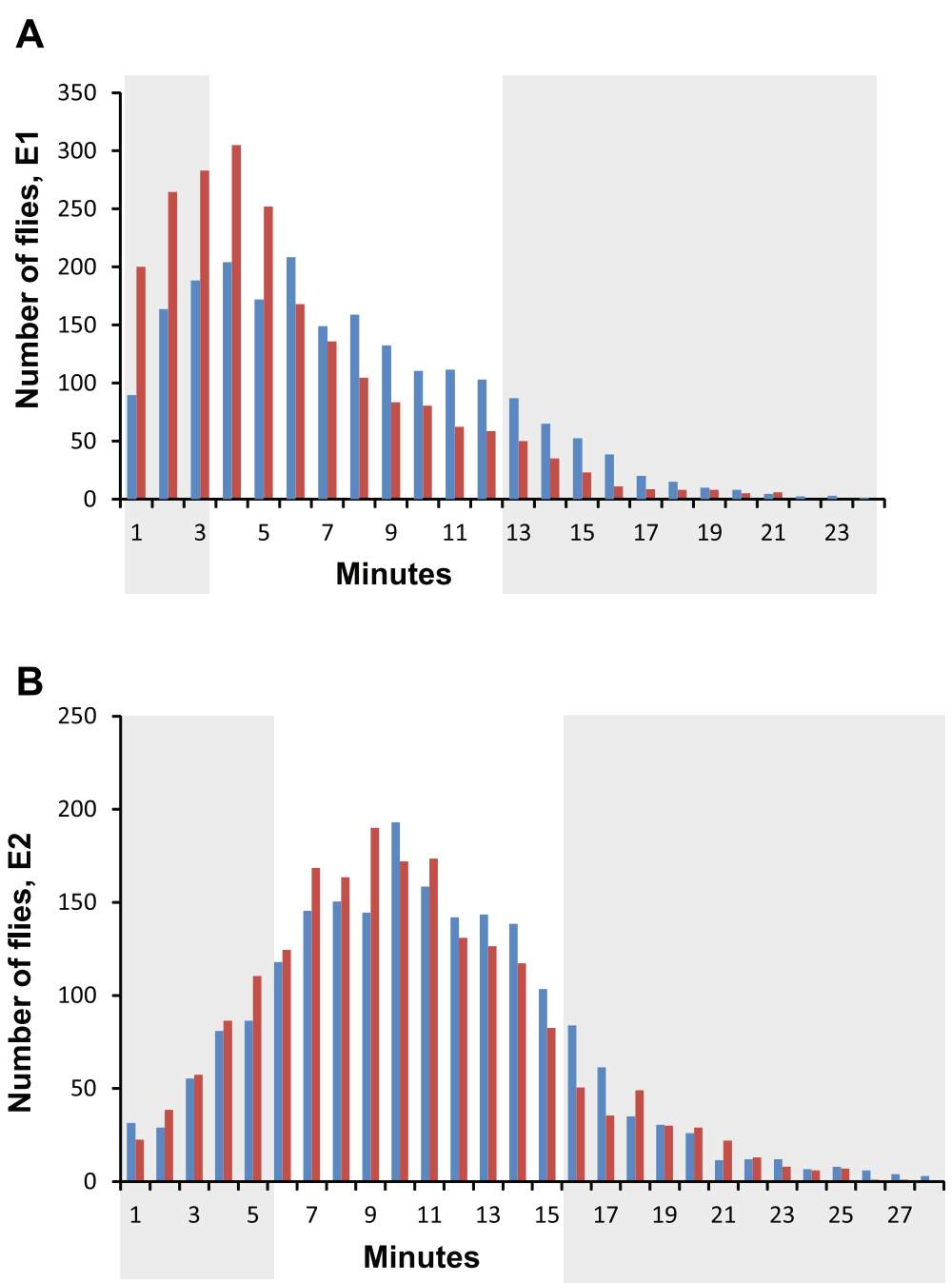

Fig. 2 Extreme QTL mapping analysis. Distribution of elution profiles for the advanced intercross population after an acute ethanol exposure (a) and after two ethanol exposures separated by a $2 \mathrm{~h}$ interval (b). Extremes (10\%) of the distributions were used for extreme QTL mapping and are shown by the shaded areas. Blue bars indicate males, red bars indicate females

appetitive reinforcement. Thus, this dopamine-mediated positive reinforcement circuit may represent an insect analog of the vertebrate mesolimbic dopamine reward system that originates in the nucleus accumbens.

\section{Comparison of DGRP and extreme QTL GWA analyses}

Applying the same logic to the extreme QTL GWA analysis as for the DGRP GWA analyses, the top candidate genes that do not meet the Bonferroni significance threshold will occur in more than one analysis. We found 119 genes tagged by top variants in one or more treatment/sex combinations in the extreme QTL GWA analysis ( $P=0.001$ by 1,000 permutations; Additional file 7 ), of which 84 (70 \%) were previously associated with alcohol sensitivity in Drosophila, mice and/or humans, and four have been functionally validated previously in Drosophila (Additional file 7).
No polymorphisms were in common between the top associations in the DGRP GWA analyses and the extreme QTL GWA analyses. This is not unexpected, since many of the polymorphisms associated with alcohol sensitivity phenotypes in the DGRP are not present in the six founding parents of the AIP, and low frequency variants that could not be tested in the DGRP that are present in the founding parents have a frequency of at least 0.167 in the AIP, and can be tested. In addition, we induced LD by crossing the six parental lines in the first generation of the AIP, and thus the local LD structure differs between the DGRP and AIP. However, even if no polymorphisms are in common, under an additive model we do expect overlap among the top genes detected in the two GWA analyses. Indeed, we found 62 genes in common between the DGRP and extreme QTL analyses, of which 42 were previously associated with alcohol 
sensitivity in Drosophila, mice and/or humans, and four have been functionally validated previously in Drosophila (Table 1; Additional file 7).

\section{Interaction networks for alcohol sensitivity}

In total, we identified 247 candidate genes for ethanol sensitivity as those genes with at least one variant significant at a Bonferroni-corrected $P$-value, as well as genes among the top associations that occurred in more than one of the DGRP, extreme QTL, or both the DGRP and extreme QTL GWA analyses (Additional file 7). The top candidate genes are highly pleiotropic and for many, genetic and physical interaction partners are known $[57,58]$ (Additional files 9 and 10). We used this information to place the candidate genes in context. A total of 58 candidate genes participate in a genetic interaction network of 127 genes (allowing one missing gene not implicated by our GWA analyses) (Fig. 3). This network includes elements of signaling pathways associated with early development, including canonical Notch, Wingless, Epidermal Growth Factor, and Hedgehog signaling pathways. Genes involved in cyclic nucleotide signaling, which has been previously associated with alcohol sensitivity $[29,59-62]$, are also present in this network. Many of the candidate genes interact with each other and may be control points that participate in a large number of additional interactions. For example, $c t$, which was tagged by a SNP that achieved Bonferroni-level significance in the DGRP GWA analysis, interacts with lola, which was implicated in the extreme QTL mapping GWA analysis. $c t$ and lola both encode transcription factors; $c t$ has been implicated as a target for Notch signaling in wing development, and lola is a major regulator of axon guidance. Similarly, a total of 95 candidate genes participate in a physical interaction network of 617 genes (again allowing for one missing gene) (Additional file 11: Figure S2).

\section{Functional validation of candidate genes}

We used mutational analysis to establish causal links between genes implicated in our DGRP and extreme QTL GWA analyses and effects on alcohol sensitivity. Based on availability of co-isogenic $M i\{E T 1\}$ and P-element insertional mutations, we tested mutations in aret, beat-Ic, bun, Calx, CG42389, if, Cyp49a1/Galphao, Lim3, mgl, otk, Pde1C, pk/CG30384, rdgA and trio. In addition, we tested UAS-RNAi lines under an Ubi-GAL4 driver targeting $K C N Q$ and fing. We found that aret, beat-Ic, CG42389, Cyp49a1/Galphao, KCNQ and pk/CG30384

Table 1 Common candidate genes for DGRP and extreme QTL GWA analyses previously associated with alcohol-related phenotypes in humans

\begin{tabular}{|c|c|c|}
\hline Drosophila gene symbol & Biological process & Human gene symbol \\
\hline CAP & Muscle attachment; sensory perception of sound & CAP2 [82] \\
\hline CG31690 & - & TMTC2 [63] \\
\hline Dys & $\begin{array}{l}\text { Imaginal disc-derived wing vein morphogenesis; neuromuscular synaptic } \\
\text { transmission; muscle organ development }\end{array}$ & DMD, UTRN $[14,63]$ \\
\hline$f z$ & $\begin{array}{l}\text { Wnt signaling pathway; signal transduction; axon extension; heart development; } \\
\text { negative regulation of Notch signaling pathway; establishment or maintenance } \\
\text { of cell polarity }\end{array}$ & FZD9 [82] \\
\hline $\mid A-2$ & Protein dephosphorylation; regulation of secretion & PTPRN2 [14] \\
\hline KCNQ & $\begin{array}{l}\text { Potassium ion transport; embryonic development via the syncytial blastoderm; } \\
\text { regulation of heart rate }\end{array}$ & KCNQ3 $[63,64]$ \\
\hline luna & Regulation of transcription, DNA-templated; mitotic sister chromatid segregation & KLF7 [110] \\
\hline milt & Axon transport of mitochondrion & TRAK2 [63] \\
\hline$m t t$ & $\begin{array}{l}\text { Phospholipase C-activating G-protein coupled receptor signaling pathway; } \\
\text { response to insecticide; adult feeding behavior }\end{array}$ & GRM5 [12] \\
\hline$N r x-I V$ & $\begin{array}{l}\text { Dorsal closure; protein localization; synaptic vesicle targeting; cell-cell junction } \\
\text { organization; establishment or maintenance of cell polarity }\end{array}$ & CHRNA5, CHRNA $7[10,83,111]$ \\
\hline Pdelc & cGMP metabolic process; cAMP metabolic process & $\operatorname{PDE} 1 C[63,64]$ \\
\hline Rbp6 & Stem cell development & $M S / 2[112]$ \\
\hline rhea & $\begin{array}{l}\text { Cell adhesion; muscle attachment; regulation of cell shape; larval somatic muscle } \\
\text { development; negative regulation of transcription, DNA-templated; phagocytosis }\end{array}$ & TLN2 [63] \\
\hline shn & $\begin{array}{l}\text { Ectoderm development; cell proliferation; learning or memory; olfactory learning; } \\
\text { transforming growth factor beta receptor signaling pathway; peripheral nervous } \\
\text { system development; positive } \\
\text { regulation of transcription from RNA polymerase II promoter }\end{array}$ & HIVEP1 [63] \\
\hline stan & $\begin{array}{l}\text { Establishment of planar polarity; cell adhesion; axonogenesis; mushroom body } \\
\text { development; Wnt signaling pathway; negative regulation of Notch signaling pathway }\end{array}$ & CELSR1 [113] \\
\hline
\end{tabular}




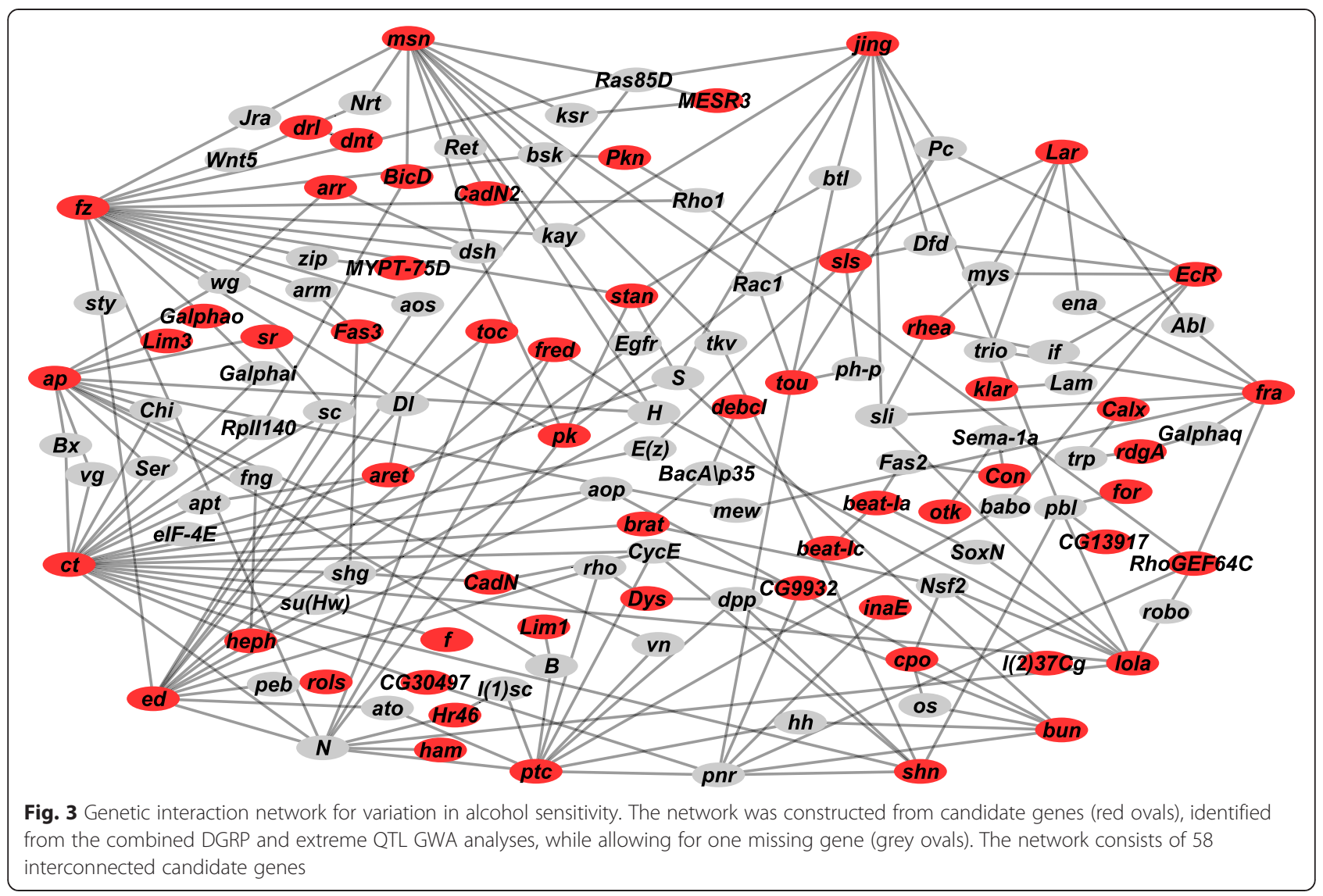

showed increased resistance after acute and/or repeated ethanol exposures; Pde1C, if, otk and $r d g A$ were more sensitive to ethanol exposures; bun, Calx, fng, Lim3, mgl and trio demonstrated either increased or decreased resistance to ethanol depending on the sex or number of ethanol exposures (Fig. 4a-b). In summary, all 13 candidate genes and the three missing genes implicated by the network analysis (if, fng and trio) had significant effects on ethanol sensitivity in at least one sex/exposure combination, indicating that our top candidate genes are enriched for true positive associations. Orthologs of eight of these functionally validated genes (bun, Calx, Galphao, KCNQ, Lim3, mgl, Pde1C, rdgA) have previously been associated with alcohol phenotypes in mouse and human studies (Additional file 7, [45, 46, 63-66]), suggesting that inferences made from Drosophila are more broadly relevant across taxa.

The extreme QTL GWA analysis identified a cluster of 21 genes located on chromosome $2 L$ between two intergenic regions ( $2 L: 19,034,444$ - 19,208,621) spanning from mib2 to $d r l$ and associated with variation in acute alcohol sensitivity (Additional file 8), including Catsup and $D d c$, which regulate the biosynthesis of dopamine, a neurotransmitter critically associated with alcohol addiction in human studies $[67,68]$ and implicated in associative conditioning in Drosophila [52, 53]. We focused only on candidate genes that have SNPs in introns, coding or 3' and 5' UTR regions. We analyzed expression levels of ten candidate genes (amd, brat, Catsup, CG10470, CG10561, l(2)37Ce, Ddc, drl, mib2 and Lim3) in pools of the three extreme sensitive and three extreme resistant DGRP lines that were used to generate the advanced intercross population by quantitative RT-PCR for both sexes, separately. We found that 15 of $20(75 \%)$ transcripts tested indeed showed altered transcript levels between the sensitive and resistant pools for both sexes (Fig. 5a-b). It is of interest to note that increased expression of the genes indicated in Fig. 5 $(\mathrm{a}-\mathrm{b})$ is associated with increased resistance. To assess whether this is significantly different from random expectation, we also measured transcript abundance levels of nine randomly selected genes that are also located on chromosome $2 L$ and have not been associated with alcohol sensitivity previously. Here, only 3 of 18 (17 \%) transcripts showed altered transcripts level between the extreme pools (Fig. $5 \mathrm{c}-\mathrm{d}$ ). The proportion of candidate genes with altered expression level is significantly greater than for randomly selected genes (Fisher's exact test, $P=0.039$ ). Thus, differences in expression levels of these candidate genes could be a causal 
A

\begin{tabular}{|c|c|c|c|c|c|c|c|c|}
\hline Candidate Genes & $\boldsymbol{G}$ & $G \times S$ & $G \times E$ & $G \times S \times E$ & M_E1 & F_E1 & M_E2 & F_E2 \\
\hline aret* & & & & & $\uparrow$ & $\uparrow$ & $\uparrow$ & $\uparrow$ \\
\hline beat-Ic* & & & & & $\uparrow$ & $\uparrow$ & $\uparrow$ & $\uparrow$ \\
\hline bun* & & & & & $\uparrow$ & $\uparrow$ & $\downarrow$ & $\downarrow$ \\
\hline Calx* & & & & & $\uparrow$ & $\downarrow$ & - & $\downarrow$ \\
\hline CG42389 & & & & & $\uparrow$ & $\uparrow$ & $\uparrow$ & $\uparrow$ \\
\hline Cyp49a1/Galphao* & & & & & $\uparrow$ & $\uparrow$ & - & - \\
\hline KCNQ & & & & & 个 & - & $\uparrow$ & $\uparrow$ \\
\hline Lim3* & & & & & $\uparrow$ & $\downarrow$ & - & $\downarrow$ \\
\hline$m g l$ & & & & & $\uparrow$ & $\uparrow$ & $\downarrow$ & - \\
\hline otk* & & & & & - & $\downarrow$ & - & - \\
\hline Pde1C & & & & & $\downarrow$ & $\downarrow$ & $\downarrow$ & $\downarrow$ \\
\hline$p k^{*} /$ CG30384 & & & & & $\uparrow$ & $\uparrow$ & $\uparrow$ & - \\
\hline$r d g A^{*}$ & & & & & $\downarrow$ & - & $\downarrow$ & $\downarrow$ \\
\hline$i f^{\#}$ & & & & & $\downarrow$ & $\downarrow$ & - & $\downarrow$ \\
\hline fng $^{\#}$ & & & & & $\downarrow$ & - & $\uparrow$ & $\uparrow$ \\
\hline trio $^{\#}$ & & & & & $\uparrow$ & - & - & $\downarrow$ \\
\hline
\end{tabular}

B
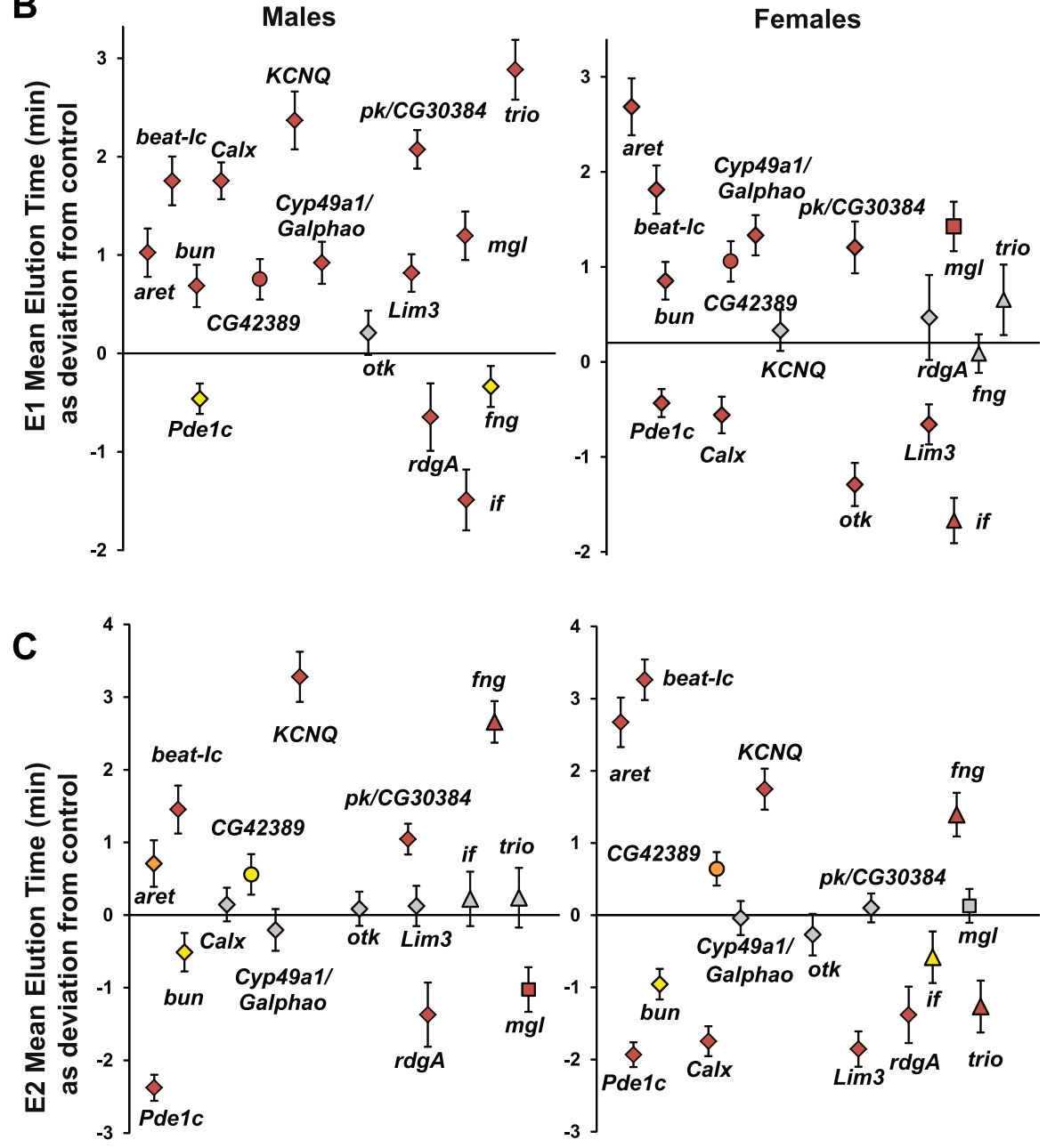

$<0.0001<0.001<0.05$ ns

Fig. 4 (See legend on next page.) 
(See figure on previous page.)

Fig. 4 Functional confirmations of candidate genes. a Candidate genes from the DGRP, extreme QTL GWA analyses and the genetic network analysis were functionally tested using transposon insertion mutations and RNAi knockdown lines. All 16 candidate genes showed significant differences from the control for at least one of the genetic terms $(G, G \times S, G \times E, G \times S \times E)$. $G$ - Genotype: mutant or control; $S$ - Sex: Male, Female; $E$ - Exposure: E1,E2; * - genes present in genetic network from Fig. 3; \# - missing gene from the genetic network. M_E1, M_E2, F_E1 and F_E2 - phenotypic effects in males (M) and females (F), respectively after an acute (E1) or repeated (E2) ethanol exposures. $\mathbf{b}$ Effects of 16 mutants of candidate genes on sensitivity to acute (top panel) and repeated (bottom panel) ethanol exposure in males (left) and females (right) compared to control. Squares indicate candidate genes found only in GWA analyses; circles indicate candidate genes found only from extreme QTL mapping analyses; Triangles indicate missing genes from the genetic network in Fig. 3. Candidate genes found in more than one analyses (GWA, extreme QTL mapping and network analysis) are shown with diamond shapes. Data are presented as the deviation of the MET of each line and sex from the appropriate control line \pm SEM, calculated as $\sqrt{S E m^{2}+S E c^{2}}$, where $m$ and $c$ are SE for mutant and control lines, respectively. The color bar indicates the significance levels for both Fig. $4 a$ and b

explanation for their association with variation in acute alcohol sensitivity.

In summary, our functional analyses suggest that networks of early neurodevelopmental genes as well as variation in catecholamine neurotransmitter levels determine natural variation in alcohol sensitivity in adult flies in this wild derived population.

\section{Discussion}

Alcohol-related phenotypes are diverse and span the spectrum from acute intoxication to long-term physiological addiction. Similarly, the physiological effects of alcohol are diverse, encompassing both intermediary metabolic pathways as well as the nervous system, where alcohol can exert both general sedative effects and elicit addiction through its actions on the dopaminergic reward system. The complexity of the physiological responses to alcohol exposure a priori predict that multiple interacting genetic factors would predispose to alcohol sensitivity; thus, a comprehensive understanding of the genetic underpinnings of alcohol sensitivity must reach beyond studies of individual genes, but take into account a genetic context in which environmentally sensitive ensembles of genes determine the phenotypic outcome.
A

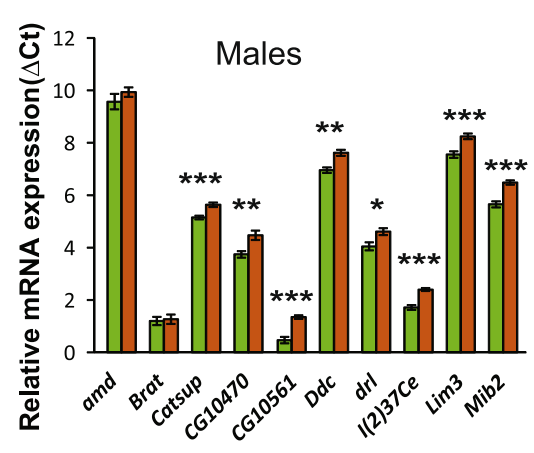

C

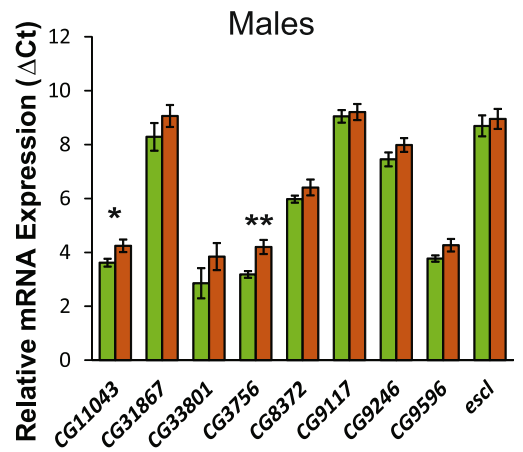

B

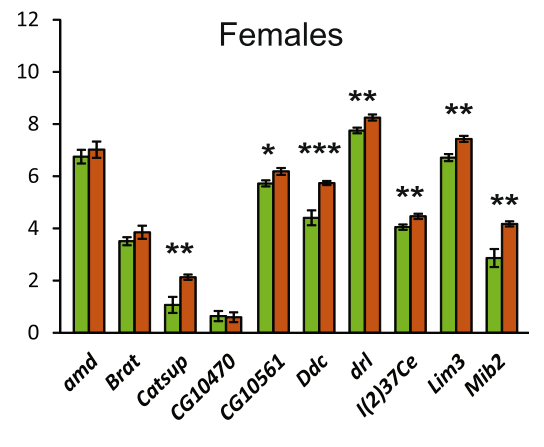

D

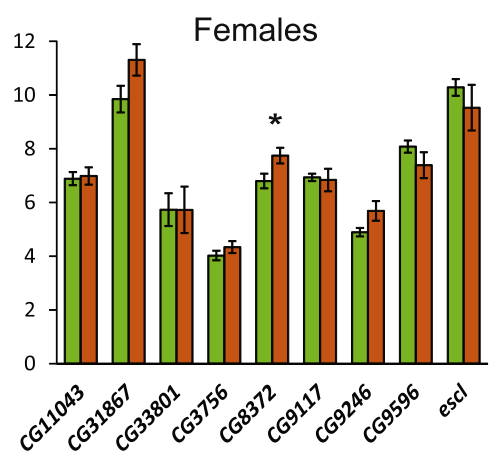

Fig. 5 Expression levels of mRNAs of a group of genes located on chromosome $2 \mathrm{~L}$ pooled across parental lines (three sensitive $v s$ three resistant lines) used to establish the advanced intercross population. Panels (a) and (b) show mRNA expression levels of candidate genes from extreme QTL mapping analyses in males and females, respectively. Panels (c) and (d) show mRNA expression levels of randomly selected genes in males and females, respectively. Green bars indicate the pool of sensitive lines, orange bars indicate the pool of resistant lines. ${ }^{*}: P<0.05$; ${ }^{* *}$ : $P<0.001$; ***: $P<0.0001$; Student's t-test 
Studies on alcohol drinking behavior, intoxication, and addiction in human populations or in mouse models have focused primarily on QTL mapping [69-72], candidate gene associations [73-81], transcriptional profiling [45-47, 65, 82-84] and, most recently, on genome-wide associations [10, 12, 14, 20, 63, 85-87]. Previous studies on the genetics of alcohol sensitivity in Drosophila employed mutagenesis screens [38], transcriptional profiling of flies before and after alcohol exposure $[35,36]$ or of lines artificially selected for high and low alcohol sensitivity [37], as well as characterization of selected candidate genes [30, 33, 51, 88-96]. Here, we have used the DGRP and a DGRP-derived AIP to perform the first GWA analyses to identify genes harboring variants that determine natural variation in individual alcohol sensitivity and variation in induction of tolerance in the Drosophila model.

Combining the results from both GWA analyses identified candidate genes associated with natural variation in alcohol sensitivity with a high degree of confidence. Causal relationships of a large fraction of these genes with phenotypic variation is apparent from the high degree with which mutations in those candidate genes recapitulate effects on alcohol related phenotypes and from previous studies which have implicated the same genes in alcohol related phenotypes both in Drosophila and vertebrates, including mice and humans (Additional file 7). Most of the genes involved in cell adhesion, neural development, cyclic nucleotide and inositol triphosphate metabolism and signaling emerged as candidate genes from prior studies as well. Human orthologs of for, KCNQ, Pde1C, phl, Pkc53E, rhea [58], fra [63], Nrx-IV [10], Pde11 [59], Pka-R2 [60] and RhoGAP68F [14] have been associated with alcohol dependence and/or alcohol consumption in human GWA studies.

We were able to connect candidate genes associated with variation in alcohol sensitivity in a genetic interaction network that encompasses early neurodevelopmental signaling pathways, including Notch, Wnt, EGFR, and Hedgehog pathways (Fig. 3). It is of interest to note that $c t$, which is a target of the Notch pathway $[97,98]$ and implicated in axonogenesis $[99,100]$, shows an association that surpasses the stringent Bonferronicorrected multiple testing threshold in the GWA analysis of the DGRP. Thus, subtle differences in neuronal connectivity determined in early development of the nervous system or possibly reflecting variation in neuroplasticity in the adult brain appear to be a major determinant of individual variation in susceptibility to alcohol exposure. Together with the genetic network that regulates neurodevelopment, our analyses implicate genes associated with neurotransmitter signaling, including dopamine and the cyclic AMP signaling pathway as factors that affect individual variation in alcohol sensitivity.
Three important insights emerge from our analyses. First, the majority of previous studies have identified widespread changes in genome wide transcript expression on exposure to alcohol [34-38]. However, due to the highly correlated nature of transcriptional coregulation networks, it is not possible to infer which changes are causal and which are co-regulated responses to causal changes. Comparison of our results with these studies (Additional file 7) indicates that the genes we identify as top candidates based on genetic polymorphisms in the GWA analyses largely overlap with genes whose expression is up- or down-regulated in response to alcohol, suggesting that these genes may be causal, affecting both transcriptional responses and whole organism behavioral responses to alcohol exposure. This hypothesis is amenable to direct experimental testing in the future. Second, the neurodevelopmental genes associated with variation in alcohol sensitivity in the Drosophila system are evolutionarily highly conserved and, thus, it is reasonable to postulate that similar orthologous networks may be associated with variation in alcohol sensitivity across phyla, including in human populations. Further, it is reasonable to surmise that alcohol-induced perturbation of early developmental networks may represent a likely target for the induction of fetal alcohol syndrome in people. Third, principles of pleiotropy and context dependence (including gene-gene interactions, sex-dependence and gene-environment interactions) are generally applicable elements that are likely characteristics of network organization across phyla.

Finally, we should note that we did not detect several genes implicated by artificial selection and mutagenesis screens for alcohol related phenotypes in Drosophila (e.g. Adh, Aldh [32, 33], amnesiac [29], white rabbit [101], hangover [102]). There could be several reasons why variants in these genes are not detected in our genome-wide association study. First, functional polymorphisms in these genes may have low frequencies in the population and thus are not captured by our GWA analysis which tests only variants with MAF $>0.05$. Second, the effects of the common variants in these genes may be small and our GWA is not sufficiently powered to detect them at the threshold used. Third, the effects of variants in these genes may be buffered by other genes in the complex physiological process of ethanol detoxification. To summarize, we can only uncover genes associated with natural variation in alcohol sensitivity that harbor polymorphisms with allele frequencies and effect sizes large enough to resolve in our analyses. Thus, genes in which mutations clearly have large effects on a trait may not be functionally variable in natural populations if they are under strong selective constraint, or they may harbor rare alleles that cannot be individually assessed by GWA analyses. 


\section{Conclusions}

GWA association analyses for ethanol sensitivity/resistance and toerance in the inbred, sequecned DGRP lines and an AIP derived from extremely sensitive and resistant lines identified mutliple genes affecting alcohol-related behaviors. These genes participate in known genetic and physical interaction networks; are in evolutionrily conserved signalling pathways, including catecholamine neurotransmitter biosynthesis and early development of the nervous system; and have been implicated in alcoholrelated phenotypes in mice and humans.

\section{Methods}

\section{Drosophila stocks}

The 205 inbred, sequenced lines of the Drosophila melanogaster Genetic Reference Panel (DGRP) [39, 40] were derived by 20 generations of full-sib mating from isofemale lines that were collected from the Raleigh, NC farmer's market. The DGRP contains 4,853,802 single nucleotide polymorphisms (SNPs) and 1,296,080 nonSNP variants (insertions and deletions) as well as 16 large polymorphic chromosomal inversions [39].

Mi\{ET1\} mutants (aret ${ }^{25234}$, beat-Ic ${ }^{25326}$, Calx $^{26124}$, CG4238925307, if ${ }^{29896}$, Cyp49a1/Galphao ${ }^{24593}$, Lim3 $^{23505}$, $m g l^{26407}$, otk ${ }^{25334}$, Pde1C $24064, p k / C G 30384^{29252}, r d g A^{26061}$, trio $\left.{ }^{29073}\right)$ and their co-isogenic control $w_{i s o}^{1118} ; 2_{\text {iso }} ; 3_{\text {iso }}^{5905}$ $[103,104]$ as well as the P\{GT1\} mutant $\left(\right.$ bun $\left.^{12584}\right)$ [105] were obtained from the Bloomington Drosophila Stock Center. The RNAi transgenic fly lines $K C N Q^{106655}$ and $f n g^{51977}$ as well as the progenitor control lines $y, w^{1118} ; P\left\{a t t P, y^{+}, w^{3}\right\}^{60100}$ and $w_{\text {iso }}^{1118} ; 2_{\text {iso }} ; 3_{\text {iso }}^{60000}$ were obtained from the Vienna Drosophila Resource Center (VDRC; [106]. The ubiquitous Ubi-Gal4 ${ }^{32551}$ driver line was obtained from the Bloomington Drosophila Stock Center. We crossed males from the transgenic UAS-RNAi line to virgin females from the driver line to suppress the expression of the target gene in hybrid F1 offspring.

Flies were reared under controlled population density and standard culture conditions on cornmeal-molassesagar medium at $25{ }^{\circ} \mathrm{C}, 60-75 \%$ relative humidity, $12 \mathrm{~h}$ light-dark cycle. Flies were not exposed to $\mathrm{CO}_{2}$ anesthesia for at least $24 \mathrm{~h}$ prior to assay.

\section{Quantitative assay for alcohol sensitivity and tolerance}

We assessed ethanol sensitivity and tolerance for all 205 DGRP lines. Each day we tested 11 randomly selected DGRP lines and a control line (Canton $S(\mathrm{~B})$ ). There were two replicate measurements for each sex per line with 70 flies per each replicate; the replicates for each line were assessed on different days. To measure alcohol sensitivity we placed 3-5 day old mated males or females in an inebriometer [25] pre-equilibrated with saturated ethanol vapor, and collected them at one-minute intervals as they eluted. We recorded elution times from the initial exposure to ethanol (E1) and two hours later after a second exposure of the same flies (E2). The mean elution time (MET) is a measure of alcohol sensitivity, and the scaled difference of MET between the second and first exposures is a measure of tolerance $(\mathrm{T})$, i.e. $T=\left(E 2_{i}-E 1_{i}\right) /(\overline{E 2}-\overline{E 1})$, where $E 2_{\mathrm{i}}$ and $\mathrm{E} 1_{\mathrm{i}}$ are, respectively the MET for E1 and E2 of line $i$, and $\overline{E 2}$ and $\overline{E 1}$ are, respectively, the population means of E2 and $\mathrm{E} 1$.

\section{Quantitative genetic and statistical analysis}

We expressed individual METs of the 205 DGRP lines as deviations from the control mean of the Canton $S$ (B) line for the appropriate date and sex. We used PROC GLM in SAS to partition variance in ethanol sensitivity after the first and second exposures among the inbred lines, pooled across sexes, according to the mixed model $Y=\mu+L+S+L \times S+\operatorname{Rep}(L \times S)+\varepsilon$, where $\mu$ is the overall mean, $S$ is the fixed effect of sex, $L$ is the random effect of line, $L \times S$ is the random effect of the sex by line interaction, $\operatorname{Rep}(L \times S)$ is the random effect of replicate, nested within $L \times S$, and $\varepsilon$ is the within-replicate (residual) variation. The total genotypic variance among lines was estimated as $\sigma_{G}^{2}=\sigma_{L}^{2}+\sigma_{L \times S}^{2}$, where $\sigma_{L}^{2}$ is the among-line variance component and $\sigma_{L \times S}^{2}$ is the variance attributable to the $L \times S$ interaction. The total phenotypic variance was estimated as $\sigma_{P}^{2}=\sigma_{G}^{2}+\sigma_{\varepsilon}^{2}$, where $\sigma_{\varepsilon}^{2}$ is the environmental variance component. We estimated broad sense heritabilities as $H^{2}=\sigma_{G}^{2} / \sigma_{P}^{2}$. We performed similar analyses separately for each sex, pooled across exposures $(E): Y=\mu+L+E+L \times E+\operatorname{Rep}(L \times E)+\varepsilon$. The total genotypic variance among lines was estimated as $\sigma_{G}^{2}=\sigma_{L}^{2}+\sigma_{L \times E}^{2}$, the total phenotypic variance was estimated as $\sigma_{P}^{2}=\sigma_{G}^{2}+\sigma_{\varepsilon}^{2}$, and the broad sense heritabilities were estimated as $H^{2}=\sigma_{G}^{2} / \sigma_{P}^{2}$.

\section{Genome-wide association analyses for alcohol sensitivity and tolerance}

We carried out a genome-wide association (GWA) analysis for each of the alcohol sensitivity and tolerance traits using the DGRP web portal (http://dgrp2.gnets.ncsu.edu/; [39]). Briefly, the raw line means were adjusted for effects of Wolbachia infection and major inversions, and subsequently used to fit a mixed effects linear model accounting for relatedness among the lines to estimate the effects of individual variants [39]. In total, we tested $1,891,456$ variants with minor allele frequencies greater than 0.05 .

\section{Extreme QTL Mapping}

To complement the GWA search, we also created an advanced intercross population to perform extreme QTL mapping [49]. To maximize genetic divergence, we 
selected three lines (DGRP_461, DGRP_721, DGRP_801) with extreme sensitivity and three lines (DGRP_142, DGRP_730, DGRP_908) with extreme resistance to alcohol exposure. Next, we crossed these lines in a partial diallel design to ensure alleles from all lines are equally represented, and maintained this advanced intercross population by random mating with a large effective population size $(N=300)$ for at least 25 generations on standard culture medium. We were able to use the same advanced intercross population for both acute (E1) and repeated alcohol exposure (E2) traits, because of the significant phenotypic correlation between the E1 and E2 phenotypes, with extreme lines being in common between the two traits. In total, we scored 2,000 males and 2,000 females for ethanol sensitivity after acute (E1) or repeated (E2) exposures, beginning at generation 25 and continuing until sufficient sampling was achieved. To measure alcohol sensitivity after the E1 exposure, we placed six sets of 100 3-5 day old mated flies of the same sex in each inebriometer column pre-equilibrated with ethanol vapor, and collected them at one-minute intervals as they eluted. We recorded elution times for each individual fly and selected the $10 \%$ most resistant and the $10 \%$ most sensitive flies. Multiple runs were performed on the same day, with sexes tested on separate days, and the 200 most resistant and most sensitive males and females were collected.

To measure alcohol sensitivity after the E2 exposure we repeated the procedure. Six sets of $1003-5$ day old mated flies of the same sex were placed in the inebriometer, flies were collected as they eluted and the elution times were recorded. Flies were allowed to recover for $2 \mathrm{~h}$, and then re-exposed to ethanol, while recording the elution times and collecting the $10 \%$ extreme flies. We collected the 200 most extreme flies over several days with sexes being scored on separate days.

DNA from the 200 most resistant and most sensitive males and females was extracted from pools of sexes separately using the Genomic-tip 100/G columns (Qiagen). Libraries were constructed from from $250 \mathrm{ng}$ of purified DNA from each of the eight pools (2 exposures $\mathrm{x} 2$ sexes x 2 pools), bar-coded (NEXflex ${ }^{\text {mi }}$ ChIP-seq Barcodes, Bioo Scientific), and sequenced on the Illumina HiSeq 2000 platform using $100 \mathrm{bp}$ paired end sequencing in a total of eight lanes. Sequence reads were aligned to the $D$. melanogaster reference genome using Burrows-Wheeler Aligner (BWA, version 0.6.2 [107]). A maximum of five mismatches were allowed and low quality bases at the end were trimmed with the "-q 13" option in BWA. The alignments were locally realigned, marked for PCR duplicates using GATK (version 2.4 [108]) and Picard tools (version 1.89) before base qualities were recalibrated using GATK. Bases passing a series of quality filters [41] were piled up to obtain counts of alleles at SNP sites where the parental lines segregate. Finally, we tested for differences between the sensitive and resistant pools using a $Z$ test, where the test statistic was calculated as $Z=\left(p_{S}-p_{R}\right) /$ $\sqrt{p_{0}\left(1-p_{0}\right)\left(2 / n+1 / d_{S}+d_{R}\right)}$. In this $Z$ test, $p_{S}$ and $p_{R}$ represent the estimated allele frequencies in the sensitive and resistant pools, respectively; $p_{0}=\left(p_{S}+p_{R}\right) / 2$ was the allele frequency under the null hypothesis $\mathrm{H}_{0}: p_{S}=p_{R} ; n$ was the total number of chromosomes in each pool; and $d_{S}$ and $d_{R}$ were the sequencing depths in the sensitive and resistant pools, respectively. $P$-values were obtained assuming that the $Z$ statistic was normally distributed under $\mathrm{H}_{0}$. We tested a total of $1,007,811$ and 978,002 SNPs in the E1 analyses of females and males, respectively; and 967,331 and 1,007,940 SNPs in the E2 analyses of males and females respectively. We used $P<5 \times 10^{-8}$ as an average Bonferroni-corrected $P$-value for all analyses.

\section{Bioinformatics analysis}

We annotated DNA variants using the gene models in Flybase release 5.49 [57]. We mapped genes to the physical and genetic interaction databases downloaded from Flybase. We then extracted subnetworks from the global networks whose edges were either a direct connection between candidate genes or bridged by only one gene not among the candidate gene list.

\section{Mutant analyses}

Mutations in 16 candidate genes were selected for functional assessment. Minos and P-element insertional mutations as well as a VDRC RNAi line and their coisogenic controls were measured for alcohol sensitivity after one (E1) and two (E2) exposures, with five replicates $(N=80$ flies per replicate) per genotype, sex, and exposure. We performed factorial fixed effect ANOVAs of form $Y=\mu+G+S+E+G \times S+G \times E+S \times E+G \times S \times$ $E+\operatorname{Rep}(G \times S \times E)+\varepsilon$ to assess the differences between mutant and control genotypes $(G)$, males and females $(S)$ and alcohol exposures $(E)$, where $\varepsilon$ is the residual variance. Significance of any of the genetic terms $(G$, $G \times S, G \times E, G \times S \times E)$ indicates an effect of the mutation on MET in at least one condition and shown with the color bar at the bottom of Fig. 4a. Mean elution times for 16 tested candidate genes are presented as the deviation of the MET of each mutant line and sex from the appropriate control line \pm SEM, calculated as $\sqrt{S E m^{2}+S E c^{2}}$, where $m$ and $c$ are $\mathrm{SE}$ for mutant and control lines, respectively (Fig. 4b). The color bar indicates the significance level for each test (Student's $t$-test).

\section{Assessment of gene expression levels}

We quantified mRNA levels by quantitative RT-PCR with the SYBR Green detection method, as described previously 
[38]. We used glyceraldehyde-3-phosphate dehydrogenase as the internal standard. We measured the expression levels of ten candidate genes (amd, brat, Catsup, CG10470, CG10561, l(2)37Ce, Ddc, drl, mib2 and Lim3) and nine negative control genes (CG11043, CG31867, CG33801, CG3756, CG8372, CG9117, CG9246, CG9596 and escl) located on chromosome $2 \mathrm{~L}$.

Six biological replicates of total RNA was extracted from the same three extreme sensitive (DGRP_461, DGRP_721, DGRP_801) and three extreme resistant (DGRP_142, DGRP_730, DGRP_908) lines used to construct the advanced intercross population, separately for males and females, using the Trizol ${ }^{\circ}$ Reagent (Ambion). cDNA was generated from $200 \mathrm{ng}$ of total RNA by reverse transcription using the High Capacity cDNA Reverse Transcription Kit with RNase Inhibitor (Applied Biosystems). Primer Express 3 software (Applied Biosystems) was used to design transcript-specific primers to amplify up to 100-bp regions of all genes of interest. Primers were designed to encompass common regions of alternative transcripts, were evaluated for hairpins and polymorphisms in the sequences that potentially may lower the affinity of the primer for the gene sequence. We encounted such problems for primers for Rpn3 and CG17572 and excluded them from further analysis (Additional file 12). Negative controls without reverse transcriptase were used to exclude potential genomic DNA contamination. Three technical replicates with six biological replicates across all lines were run on the same 384-well microtiter plate, including Gpdh as internal standard. Expression of each gene in each biological replicate for each DGRP line and for each sex was normalized relative to the appropriate $G p d h$ expression level using $\Delta \mathrm{Ct}$ values, according to $\mathrm{ABI}$ User Bulletin no. 2 [109]. Statistically significant differences in gene expression levels between sensitive and resistant pools were determined by Student's $t$-tests on $\Delta \mathrm{Ct}$ values.

\section{Additional files}

Additional file 1: Table S1. Analyses of variance of alcohol sensitivity of 205 DGRP lines. (DOCX $20 \mathrm{~kb}$ )

Additional file 2: METs for each DGRP line for males and females, by treatment (E1, E2, T). (XLSX $73 \mathrm{~kb})$

Additional file 3: Figure S1. Phenotypic correlations among METs in males and females and across treatments. (A) E1 females and males $\left(r_{p}=0.78\right)$. (B) E2 females and males $\left(r_{p}=0.79\right)$. (C) Females, E1 and E2 $\left(r_{P}=0.7\right)$. D) Males, E1 and E2 $\left(r_{P}=0.7\right)$. (E) Tolerance, females and males $\left(r_{P}=0.67\right)$. (PDF $313 \mathrm{~kb}$ )

Additional file 4: GWA analyses of MET in the DGRP following a single ethanol exposure (E1). All variants significant at a nominal $P$-value $<5 \times 10^{-5}$ in any test are listed. Effects are one-half the mean difference in MET between the major and minor allele classes. (XLSX 69 kb)

Additional file 5: GWA analyses of MET in the DGRP following a second ethanol exposure (E2). All variants significant at a nominal
$P$-value $<5 \times 10^{-5}$ in any test are listed. Effects are one-half the mean difference in MET between the major and minor allele classes. (XLSX 68 kb)

Additional file 6: GWA analyses of tolerance (T) in the DGRP. All variants significant at a nominal $P$-value $<5 \times 10^{-5}$ in any test are listed. Effects are one-half the mean difference in MET between the major and minor allele classes. (XLSX $74 \mathrm{~kb}$ )

Additional file 7: Candidate genes associated with alcohol sensitivity from GWA studies on the DGRP (DGRP_) and/or from the extreme QTL (xQTL_) mapping analyses. F: females, M: males; D: difference between males and females. E1: acute ethanol exposure; E2: repeated ethanol exposure; $T$ : induction of tolerance. Numbers in parenthesis indicate are the number of shared polymorphism in the same gene. References to studies in which the same gene or orthologous gene have been implicated in alcohol sensitivity are given in square brackets. (XLSX $37 \mathrm{~kb}$ )

Additional file 8: Extreme QTL mapping GWA analyses in the AIP. Information is given for the top variants in each analysis, as well as corresponding information for the same variants in the other analyses. $f$ denotes allele frequency and subscripts $R$ and $S$ denote resistant and sensitive pools, respectively. E1 is for acute ethanol exposure and E2 indicates the second ethanol exposure. (XLSX $682 \mathrm{~kb}$ )

Additional file 9: Genetic interactions among top candidate genes for alcohol sensitivity. The candidate gene column indicates which of the interacting partners are candidate genes (Yes) and which have been recruited to the network via their physical interactions with a candidate gene (No). (XLSX 19 kb)

Additional file 10: Physical interactions among top candidate genes for alcohol sensitivity. The candidate gene column indicates which of the interacting partners are candidate genes (Yes) and which have been recruited to the network via their physical interactions with a candidate gene (No). (XLSX $78 \mathrm{~kb}$ )

Additional file 11: Figure S2. Protein-protein interaction network for variation in alcohol sensitivity. The network was constructed from candidate genes (red ovals), identified from the combined DGRP and extreme QTL GWA analyses, while allowing for one missing gene (grey ovals). The candidate genes with the most interactions are depicted on the perimeter of the interaction network. (PDF $825 \mathrm{~kb}$ )

Additional file 12: Quantitative qRT-PCR primer sequences. (XLSX $11 \mathrm{~kb})$

\section{Abbreviations}

AIP: Advanced Intercross Population; DGRP: Drosophila melanogaster Genetic Reference Panel; MET: Mean elution time; E1: Acute exposure to alcohol; E2: Repeated exposure to alcohol; T: Tolerance; GWA: Genome-wide association; SNP: Single nucleotide polymorphism.

\section{Competing interests}

The authors declare that they have no competing interests.

\section{Authors' contributions}

TVM, TFCM and RRHA designed the experiments. TVM, VAP and TW performed the experiments. TVM and $\mathrm{WH}$ analyzed the data. TVM, WH, TFCM and RRHA wrote the manuscript. All authors read and approved the final manuscript.

\section{Acknowledgements}

We would like to thank Eugenea V. Zhirnov and Morgan Davis for technical assistance and Drs. Michael M. Magwire, Mary Anna Carbone and Shanshan Zhou for helpful discussions. This work was supported by National Institutes of Health grant R01 AA016560 to TFCM and RRHA.

\section{Author details}

${ }^{1}$ Department of Biological Sciences, W. M. Keck Center for Behavioral Biology and Program in Genetics, North Carolina State University, Box 7614, Raleigh, NC 27695, USA. ${ }^{2}$ Department of Biochemistry and Physiology, School of Bioscience and Medicine, Faculty of Health and Medical Sciences, University of Surrey, Guildford, Surrey GU2 7XH, UK. 
Received: 23 July 2015 Accepted: 13 October 2015

Published online: 26 October 2015

\section{References}

1. Agrawal A, Freedman ND, Cheng YC, Lin P, Shaffer JR, Sun Q, et al. Measuring alcohol consumption for genomic meta-analyses of alcohol intake: opportunities and challenges. Am J Clin Nutr. 2012;95:539-47.

2. Agrawal A, Grant JD, Littlefield A, Waldron M, Pergadia ML, Lynskey MT, et al. Developing a quantitative measure of alcohol consumption for genomic studies on prospective cohorts. J Stud Alcohol Drugs. 2009;70:157-68.

3. Linneberg A, Gonzalez-Quintela A, Vidal C, Jorgensen T, Fenger M, Hansen $T$, et al. Genetic determinants of both ethanol and acetaldehyde metabolism influence alcohol hypersensitivity and drinking behaviour among Scandinavians. Clin Exp Allergy. 2010;40:123-30.

4. Littlefield AK, Agrawal A, Ellingson JM, Kristjansson S, Madden PA, Bucholz KK, et al. Does variance in drinking motives explain the genetic overlap between personality and alcohol use disorder symptoms? A twin study of young women. Alcohol Clin Exp Res. 2011;35:2242-50.

5. Edenberg HJ. Genetics of Alcohol Use Disorders. In: Miller PM, editor. Biological Research on Addiction, vol. 2. Academic Press: Elsevier Science \& Technology Books; 2013. p. 500-8.

6. Cao J, LaRocque E, Li D. Associations of the 5-hydroxytryptamine (serotonin) receptor $1 \mathrm{~B}$ gene (HTR1B) with alcohol, cocaine, and heroin abuse. Am J Med Genet B Neuropsychiatr Genet. 2013;162B:169-76.

7. Dick DM, Wang JC, Plunkett J, Aliev F, Hinrichs A, Bertelsen S, et al. Familybased association analyses of alcohol dependence phenotypes across DRD2 and neighboring gene ANKK1. Alcohol Clin Exp Res. 2007;31:1645-53.

8. Lind PA, Eriksson CJ, Wilhelmsen KC. The role of aldehyde dehydrogenase-1 (ALDH1A1) polymorphisms in harmful alcohol consumption in a Finnish population. Hum Genomics. 2008;3:24-35.

9. Mulligan CJ, Robin RW, Osier MV, Sambuughin N, Goldfarb LG, Kittles RA, et al. Allelic variation at alcohol metabolism genes (ADH1B, ADH1C, ALDH2) and alcohol dependence in an American Indian population. Hum Genet. 2003;113:325-36.

10. Lind PA, Macgregor S, Vink JM, Pergadia ML, Hansell NK, de Moor MH, et al. A genomewide association study of nicotine and alcohol dependence in Australian and Dutch populations. Twin Res Hum Genet. 2010;13:10-29.

11. Agrawal A, Edenberg HJ, Foroud T, Bierut LJ, Dunne G, Hinrichs AL, et al. Association of GABRA2 with drug dependence in the collaborative study of the genetics of alcoholism sample. Behav Genet. 2006;36:640-50.

12. Bierut $\amalg$, Agrawal A, Bucholz KK, Doheny KF, Laurie C, Pugh E, et al. A genome-wide association study of alcohol dependence. Proc Natl Acad Sci U S A. 2010;107:5082-7.

13. Bierut LJ, Goate AM, Breslau N, Johnson EO, Bertelsen S, Fox L, et al. $A D H 1 B$ is associated with alcohol dependence and alcohol consumption in populations of European and African ancestry. Mol Psychiatry. 2012;17:445-50.

14. Baik I, Cho NH, Kim SH, Han BG, Shin C. Genome-wide association studies identify genetic loci related to alcohol consumption in Korean men. Am J Clin Nutr. 2011;93:809-16.

15. Wang KS, Liu X, Zhang Q, Pan Y, Aragam N, Zeng M. A meta-analysis of two genome-wide association studies identifies 3 new loci for alcohol dependence. J Psychiatr Res. 2011;45:1419-25.

16. Morozova TV, Mackay TFC, Anholt RRH. Genetics and genomics of alcohol sensitivity. Mol Genet Genomics. 2014;289:253-69.

17. Ducci F, Goldman D. Genetic approaches to addiction: genes and alcohol. Addiction. 2008;103:1414-28.

18. Morozova TV, Goldman D, Mackay TFC, Anholt RRH. The genetic basis of alcoholism: multiple phenotypes, many genes, complex networks. Genome Biol. 2012;13:239.

19. Uhl GR, Drgon T, Johnson C, Fatusin OO, Liu QR, Contoreggi C, et al. "Higher order" addiction molecular genetics: convergent data from genome-wide association in humans and mice. Biochem Pharmacol. 2008;75:98-111.

20. Treutlein J, Rietschel M. Genome-wide association studies of alcohol dependence and substance use disorders. Curr Psychiatry Rep. 2011;13:147-55.

21. Zhao Z, Guo AY, van den Oord EJ, Aliev F, Jia P, Edenberg HJ, et al. Multi-species data integration and gene ranking enrich significant results in an alcoholism genome-wide association study. BMC Genomics. 2012;13 Suppl 8:S16.

22. Barkley-Levenson AM, Crabbe JC. Bridging animal and human models: Translating from (and to) animal genetics. Alcohol Res. 2012;34:325-35.
23. Devineni AV, Heberlein U. The evolution of Drosophila melanogaster as a model for alcohol research. Annu Rev Neurosci. 2013;36:121-38.

24. Kaun KR, Devineni AV, Heberlein U. Drosophila melanogaster as a model to study drug addiction. Hum Genet. 2012;131:959-75.

25. Weber KE. An apparatus for measurement of resistance to gas-phase reagents. Drosophila Inform Serv. 1988;67:90-2.

26. Heberlein U, Wolf FW, Rothenfluh A, Guarnieri DJ. Molecular genetic analysis of ethanol intoxication in Drosophila melanogaster. Integr Comp Biol. 2004;44:269-74.

27. Scholz H, Mustard JA. Invertebrate models of alcoholism. Curr Top Behav Neurosci. 2013;13:433-57.

28. Scholz H, Ramond J, Singh CM, Heberlein U. Functional ethanol tolerance in Drosophila. Neuron. 2000;28:261-71.

29. Moore MS, DeZazzo J, Luk AY, Tully T, Singh CM, Heberlein U. Ethanol intoxication in Drosophila: Genetic and pharmacological evidence for regulation by the CAMP signaling pathway. Cell. 1998;93:997-1007.

30. Park SK, Sedore SA, Cronmiller C, Hirsh J. Type II CAMP-dependent protein kinase-deficient Drosophila are viable but show developmental, circadian, and drug response phenotypes. J Biol Chem. 2000;275:20588-96.

31. Gibson JB, Wilks AV. The alcohol dehydrogenase polymorphism of Drosophila melanogaster in relation to environmental ethanol, ethanol tolerance and alcohol dehydrogenase activity. Heredity (Edinb). 1988;60(Pt 3):403-14.

32. Fry JD, Donlon K, Saweikis M. A worldwide polymorphism in aldehyde dehydrogenase in Drosophila melanogaster: evidence for selection mediated by dietary ethanol. Evolution. 2008;62:66-75.

33. Fry JD, Saweikis M. Aldehyde dehydrogenase is essential for both adult and lanal ethanol resistance in Drosophila melanogaster. Genet Res. 2006;87:87-92

34. Morozova TV, Ayroles JF, Jordan KW, Duncan LH, Carbone MA, Lyman RF, et al. Alcohol sensitivity in Drosophila: translational potential of systems genetics. Genetics. 2009;183:733-45. 731SI-712SI.

35. Morozova TV, Anholt RRH, Mackay TFC. Transcriptional response to alcohol exposure in Drosophila melanogaster. Genome Biol. 2006;7:R95.

36. Kong EC, Allouche L, Chapot PA, Vranizan K, Moore MS, Heberlein U, et al. Ethanol-regulated genes that contribute to ethanol sensitivity and rapid tolerance in Drosophila. Alcohol Clin Exp Res. 2010;34:302-16.

37. Morozova TV, Anholt RRH, Mackay TFC. Phenotypic and transcriptional response to selection for alcohol sensitivity in Drosophila melanogaster. Genome Biol. 2007;8:R231.

38. Morozova TV, Mackay TFC, Anholt RRH. Transcriptional networks for alcohol sensitivity in Drosophila melanogaster. Genetics. 2011;187:1193-205.

39. Huang W, Massouras A, Inoue Y, Peiffer J, Ramia M, Tarone AM, et al. Natural variation in genome architecture among 205 Drosophila melanogaster Genetic Reference Panel lines. Genome Res. 2014;24:1193-208.

40. Mackay TFC, Richards S, Stone EA, Barbadilla A, Ayroles JF, Zhu D, et al. The Drosophila melanogaster Genetic Reference Panel. Nature. 2012;482:173-8.

41. Huang W, Richards S, Carbone MA, Zhu D, Anholt RRH, Ayroles JF, et al. Epistasis dominates the genetic architecture of Drosophila quantitative traits. Proc Natl Acad Sci U S A. 2012;109:15553-9.

42. Swarup S, Huang W, Mackay TFC, Anholt RRH. Analysis of natural variation reveals neurogenetic networks for Drosophila olfactory behavior. Proc Natl Acad Sci U S A. 2013;110:1017-22.

43. Falconer DS, Mackay TFC. Introduction to Quantitative Genetics. 4th ed. 1996.

44. Ghezzi A, Krishnan HR, Lew L, Prado 3rd FJ, Ong DS, Atkinson NS. Alcoholinduced histone acetylation reveals a gene network involved in alcohol tolerance. PLoS Genet. 2013;9, e1003986.

45. Mulligan MK, Ponomarev I, Hitzemann RJ, Belknap JK, Tabakoff B, Harris RA, et al. Toward understanding the genetics of alcohol drinking through transcriptome meta-analysis. Proc Natl Acad Sci USA. 2006;103:6368-73.

46. Mulligan MK, Rhodes JS, Crabbe JC, Mayfield RD, Adron Harris R, Ponomarev I. Molecular profiles of drinking alcohol to intoxication in C57BL/6 J mice. Alcohol Clin Exp Res. 2011;35:659-70.

47. Lewohl JM, Wang L, Miles MF, Zhang L, Dodd PR, Harris RA. Gene expression in human alcoholism: microarray analysis of frontal cortex. Alcohol Clin Exp Res. 2000;24:1873-82.

48. Manolio TA, Collins FS, Cox NJ, Goldstein DB, Hindorff LA, Hunter DJ, et al. Finding the missing heritability of complex diseases. Nature. 2009;461:747-53.

49. Ehrenreich IM, Torabi N, Jia Y, Kent J, Martis S, Shapiro JA, et al. Dissection of genetically complex traits with extremely large pools of yeast segregants. Nature. 2010;464:1039-42.

50. Awofala AA. Genetic approaches to alcohol addiction: gene expression studies and recent candidates from Drosophila. Invert Neurosci. 2010;11:1-7. 
51. Urizar NL, Yang Z, Edenberg HJ, Davis RL. Drosophila homer is required in a small set of neurons including the ellipsoid body for normal ethanol sensitivity and tolerance. J Neurosci. 2007;27:4541-51.

52. Schwaerzel M, Monastirioti M, Scholz H, Friggi-Grelin F, Birman S, Heisenberg M. Dopamine and octopamine differentiate between aversive and appetitive olfactory memories in Drosophila. J Neurosci. 2003;23:10495-502.

53. Aso Y, Herb A, Ogueta M, Siwanowicz I, Templier T, Friedrich AB, et al. Three dopamine pathways induce aversive odor memories with different stability. PLoS Genet. 2012;8, e1002768.

54. Kaun KR, Azanchi R, Maung Z, Hirsh J, Heberlein U. A Drosophila model for alcohol reward. Nat Neurosci. 2011;14:612-9.

55. Liu C, Placais PY, Yamagata N, Pfeiffer BD, Aso Y, Friedrich AB, et al. A subset of dopamine neurons signals reward for odour memory in Drosophila. Nature. 2012;488:512-6.

56. Burke CJ, Huetteroth W, Owald D, Perisse E, Krashes MJ, Das G, et al. Layered reward signalling through octopamine and dopamine in Drosophila. Nature. 2012;492:433-7.

57. McQuilton P, St Pierre SE, Thurmond J. FlyBase 101-the basics of navigating FlyBase. Nucleic Acids Res. 2012;40:D706-714.

58. St Pierre SE, Ponting L, Stefancsik R, McQuilton P. FlyBase 102-advanced approaches to interrogating FlyBase. Nucleic Acids Res. 2014;42:D780-788.

59. Maas Jr JW, Vogt SK, Chan GC, Pineda W, Storm DR, Muglia LJ. Calciumstimulated adenylyl cyclases are critical modulators of neuronal ethanol sensitivity. J Neurosci. 2005;25:4118-26.

60. Blednov YA, Benavidez JM, Black M, Harris RA. Inhibition of phosphodiesterase 4 reduces ethanol intake and preference in C57BL/6 J mice. Front Neurosci. 2014;8:129.

61. Diamond I, Gordon AS. Cellular and molecular neuroscience of alcoholism. Physiol Rev. 1997;77:1-20.

62. Wand G, Levine M, Zweifel L, Schwindinger W, Abel T. The CAMP-protein kinase A signal transduction pathway modulates ethanol consumption and sedative effects of ethanol. J Neurosci. 2001;21:5297-303.

63. Edenberg HJ, Koller DL, Xuei X, Wetherill L, McClintick JN, Almasy L, et al. Genome-wide association study of alcohol dependence implicates a region on chromosome 11. Alcohol Clin Exp Res. 2010;34:840-52.

64. Liu QR, Drgon T, Johnson C, Walther D, Hess J, Uhl GR. Addiction molecular genetics: 639,401 SNP whole genome association identifies many "cell adhesion" genes. Am J Med Genet B Neuropsychiatr Genet. 2006;141B:918-25.

65. Kerns RT, Ravindranathan A, Hassan S, Cage MP, York T, Sikela JM, et al. Ethanol-responsive brain region expression networks: implications for behavioral responses to acute ethanol in DBA/2 J versus C57BL/6 J mice. J Neurosci. 2005;25:2255-66.

66. Wolstenholme JT, Warner JA, Capparuccini MI, Archer KJ, Shelton KL, Miles MF. Genomic analysis of individual differences in ethanol drinking: evidence for non-genetic factors in C57BL/6 mice. PLoS One. 2011;6, e21100.

67. Tabakoff B, Hoffman PL. The neurobiology of alcohol consumption and alcoholism: an integrative history. Pharmacol Biochem Behav. 2013;113:20-37.

68. Rietschel M, Treutlein J. The genetics of alcohol dependence. Ann N Y Acad Sci. 2013;1282:39-70

69. Buck KJ, Milner LC, Denmark DL, Grant SG, Kozell LB. Discovering genes involved in alcohol dependence and other alcohol responses: role of animal models. Alcohol Res. 2012;34:367-74.

70. Buck KJ, Rademacher BS, Metten P, Crabbe JC. Mapping murine loci for physical dependence on ethanol. Psychopharmacology (Berl). 2002;160:398-407.

71. Kozell LB, Walter NA, Milner LC, Wickman K, Buck KJ. Mapping a barbiturate withdrawal locus to a $0.44 \mathrm{Mb}$ interval and analysis of a novel null mutant identify a role for Kcnj9 (GIRK3) in withdrawal from pentobarbital, zolpidem, and ethanol. J Neurosci. 2009;29:11662-73.

72. Ehlers CL, Walter NA, Dick DM, Buck KJ, Crabbe JC. A comparison of selected quantitative trait loci associated with alcohol use phenotypes in humans and mouse models. Addict Biol. 2010;15:185-99.

73. Kapfhamer D, Taylor S, Zou ME, Lim JP, Kharazia V, Heberlein U. Taok2 controls behavioral response to ethanol in mice. Genes Brain Behav. 2013; 12:87-97.

74. Fehr C, Shirley RL, Crabbe JC, Belknap JK, Buck KJ, Phillips TJ. The syntaxin binding protein 1 gene (Stxbp 1) is a candidate for an ethanol preference drinking locus on mouse chromosome 2. Alcohol Clin Exp Res. 2005;29:708-20.

75. Crabbe JC, Phillips TJ, Harris RA, Arends MA, Koob GF. Alcohol-related genes: contributions from studies with genetically engineered mice. Addict Biol. 2006;11:195-269.
76. Dick DM, Aliev F, Wang JC, Saccone S, Hinrichs A, Bertelsen S, et al. A Systematic single nucleotide polymorphism screen to fine-map alcohol dependence genes on chromosome 7 identifies association with a novel susceptibility gene ACN9. Biol Psychiatry. 2008;63:1047-53.

77. Yang BZ, Kranzler HR, Zhao H, Gruen JR, Luo X, Gelernter J. Haplotypic variants in DRD2, ANKK1, TTC12, and NCAM1 are associated with comorbid alcohol and drug dependence. Alcohol Clin Exp Res. 2008;32:2117-27.

78. Li D, Zhao H, Gelernter J. Strong protective effect of the aldehyde dehydrogenase gene (ALDH2) 504lys (*2) allele against alcoholism and alcohol-induced medical diseases in Asians. Hum Genet. 2012;131:725-37.

79. Lin Z, Walther D, Yu XY, Li S, Drgon T, Uhl GR. SLC18A2 promoter haplotypes and identification of a novel protective factor against alcoholism. Hum Mol Genet. 2005;14:1393-404.

80. Karpyak VM, Kim JH, Biernacka JM, Wieben ED, Mrazek DA, Black JL, et al. Sequence variations of the human MPDZ gene and association with alcoholism in subjects with European ancestry. Alcohol Clin Exp Res. 2009;33:712-21.

81. Hendershot CS, Lindgren KP, Liang T, Hutchison KE. COMT and ALDH2 polymorphisms moderate associations of implicit drinking motives with alcohol use. Addict Biol. 2011;17:192-201.

82. Mayfield RD, Lewohl JM, Dodd PR, Herlihy A, Liu J, Harris RA. Patterns of gene expression are altered in the frontal and motor cortices of human alcoholics. J Neurochem. 2002;81:802-13.

83. Iwamoto K, Bundo M, Yamamoto M, Ozawa H, Saito T, Kato T. Decreased expression of NEFH and PCP4/PEP19 in the prefrontal cortex of alcoholics. Neurosci Res. 2004:49:379-85.

84. Vanderlinden LA, Saba LM, Kechris K, Miles MF, Hoffman PL, Tabakoff B. Whole brain and brain regional coexpression network interactions associated with predisposition to alcohol consumption. PLoS One. 2013;8, e68878.

85. Pan Y, Luo X, Liu X, Wu LY, Zhang Q, Wang L, et al. Genome-wide association studies of maximum number of drinks. J Psychiatr Res. 2013;47:1717-24.

86. Treutlein J, Cichon S, Ridinger M, Wodarz N, Soyka M, Zill P, et al. Genomewide association study of alcohol dependence. Arch Gen Psychiatry. 2009;66:773-84

87. Zuo L, Gelernter J, Zhang CK, Zhao H, Lu L, Kranzler HR, et al. Genome-wide association study of alcohol dependence implicates KIAA0040 on chromosome 1q. Neuropsychopharmacology. 2012;37:557-66.

88. Wen T, Parrish CA, Xu D, Wu Q, Shen P. Drosophila neuropeptide F and its receptor, NPFR1, define a signaling pathway that acutely modulates alcohol sensitivity. Proc Natl Acad Sci U S A. 2005;102:2141-6.

89. Maiya R, Lee S, Berger KH, Kong EC, Slawson JB, Griffith LC, et al. DlgS97/ SAP97, a neuronal isoform of discs large, regulates ethanol tolerance. PLoS One. 2012;7, e48967.

90. Cheng Y, Endo K, Wu K, Rodan AR, Heberlein U, Davis RL. Drosophila fasciclinll is required for the formation of odor memories and for normal sensitivity to alcohol. Cell. 2001;105:757-68.

91. Corl AB, Berger KH, Ophir-Shohat G, Gesch J, Simms JA, Bartlett SE, et al. Happyhour, a Ste20 family kinase, implicates EGFR signaling in ethanolinduced behaviors. Cell. 2009;137:949-60.

92. Cowmeadow RB, Krishnan HR, Atkinson NS. The slowpoke gene is necessary for rapid ethanol tolerance in Drosophila. Alcohol Clin Exp Res. 2005;29:1777-86.

93. Davis RL, Kiger Jr JA. Dunce mutants of Drosophila melanogaster: mutants defective in the cyclic AMP phosphodiesterase enzyme system. J Cell Biol. 1981;90:101-7.

94. Dzitoyeva S, Dimitrijevic N, Manev H. Gamma-aminobutyric acid B receptor 1 mediates behavior-impairing actions of alcohol in Drosophila: adult RNA interference and pharmacological evidence. Proc Natl Acad Sci U S A. 2003;100:5485-90.

95. Eddison M, Guarnieri DJ, Cheng L, Liu CH, Moffat KG, Davis G, et al. arouser reveals a role for synapse number in the regulation of ethanol sensitivity. Neuron. 2011;70:979-90.

96. Feany MB, Quinn WG. A neuropeptide gene defined by the Drosophila memory mutant amnesiac. Science. 1995;268:869-73.

97. Pitsouli C, Perrimon N. The homeobox transcription factor cut coordinates patterning and growth during Drosophila airway remodeling. Sci Signal. 2013;6:ra12.

98. Sun J, Deng WM. Notch-dependent downregulation of the homeodomain gene cut is required for the mitotic cycle/endocycle switch and cell differentiation in Drosophila follicle cells. Development. 2005;132:4299-308. 
99. Jinushi-Nakao S, Arvind R, Amikura R, Kinameri E, Liu AW, Moore AW. Knot/ Collier and cut control different aspects of dendrite cytoskeleton and synergize to define final arbor shape. Neuron. 2007;56:963-78.

100. Iyer SC, Ramachandran lyer EP, Meduri R, Rubaharan M, Kuntimaddi A Karamsetty M, et al. Cut, via CrebA, transcriptionally regulates the COPII secretory pathway to direct dendrite development in Drosophila. J Cell Sci. 2013;126:4732-45

101. Rothenfluh A, Threlkeld RJ, Bainton RJ, Tsai LT, Lasek AW, Heberlein U. Distinct behavioral responses to ethanol are regulated by alternate RhoGAP18B isoforms. Cell. 2006;127:199-211.

102. Scholz H, Franz M, Heberlein U. The hangover gene defines a stress pathway required for ethanol tolerance development. Nature. 2005;436:845-7.

103. Ryder E, Blows F, Ashburner M, Bautista-Llacer R, Coulson D, Drummond J, et al. The DrosDel collection: a set of $P$-element insertions for generating custom chromosomal aberrations in Drosophila melanogaster. Genetics. 2004;167:797-813.

104. Bellen HJ, Levis RW, He Y, Carlson JW, Evans-Holm M, Bae E, et al. The Drosophila Gene Disruption Project: progress using transposons with distinctive site specificities. Genetics. 2011;188:731-43.

105. Bellen HJ, Levis RW, Liao G, He Y, Carlson JW, Tsang G, et al. The BDGP Gene Disruption Project: single transposon insertions associated with $40 \%$ of Drosophila genes. Genetics. 2004;167:761-81.

106. Dietzl G, Chen D, Schnorrer F, Su KC, Barinova Y, Fellner M, et al. A genomewide transgenic RNAi library for conditional gene inactivation in Drosophila. Nature. 2007:448:151-6.

107. Li H, Durbin R. Fast and accurate short read alignment with BurrowsWheeler transform. Bioinformatics. 2009;25:1754-60

108. DePristo MA, Banks E, Poplin R, Garimella KV, Maguire JR, Hartl C, et al. A framework for variation discovery and genotyping using next-generation DNA sequencing data. Nat Genet. 2011:43:491-8.

109. Applied Biosystems, A. Relative quantitation of gene expression. User Bulletin No. 2. Foster City, CA: ABI PRISM 7700 Sequence Detection System; 2001

110. Liu J, Lewohl JM, Harris RA, lyer VR, Dodd PR, Randall PK, et al. Patterns of gene expression in the frontal cortex discriminate alcoholic from nonalcoholic individuals. Neuropsychopharmacology. 2006;31:1574-82.

111. Flatscher-Bader T, van der Brug M, Hwang JW, Gochee PA, Matsumoto I, Niwa $\mathrm{S}$, et al. Alcohol-responsive genes in the frontal cortex and nucleus accumbens of human alcoholics. J Neurochem. 2005;93:359-70.

112. Johnson C, Drgon T, Liu QR, Walther D, Edenberg H, Rice J, et al. Pooled association genome scanning for alcohol dependence using 104,268 SNPs: validation and use to identify alcoholism vulnerability loci in unrelated individuals from the collaborative study on the genetics of alcoholism. Am J Med Genet B Neuropsychiatr Genet. 2006;141B:844-53.

113. Sokolov BP, Jiang L, Trivedi NS, Aston C. Transcription profiling reveals mitochondrial, ubiquitin and signaling systems abnormalities in postmortem brains from subjects with a history of alcohol abuse or dependence. J Neurosci Res. 2003;72:756-67.

\section{Submit your next manuscript to BioMed Central and take full advantage of:}

- Convenient online submission

- Thorough peer review

- No space constraints or color figure charges

- Immediate publication on acceptance

- Inclusion in PubMed, CAS, Scopus and Google Scholar

- Research which is freely available for redistribution 